\title{
Reversible and irreversible dimensional changes of heat-treated wood during alternate
} wetting and drying

\section{Eiichi OBATAYA ${ }^{1}$ and Takashi HIGASHIHARA ${ }^{2}$}

${ }^{1}$ Graduate School of Life and Environmental Sciences, Tsukuba University

Tsukuba, 305-8572, Ibaraki, Japan

obataya.eiichi.fu@u.tsukuba.ac.jp

${ }^{2}$ Graduate School of Education, Joetsu University of Education

Joetsu, 943-8512, Niigata, Japan

\begin{abstract}
Spruce wood specimens were heat-treated in saturated water vapor (steaming) and in the absence of moisture (dry heating) at $120-180^{\circ} \mathrm{C}$, and their wet volumes were measured during alternate wetting and drying cycles. After the first wetting and drying cycle, the wet volume of steamed wood decreased, and then remained unchanged during the following alternate wetting and drying cycles. The wet volume regained its initial level when soaked in dimethyl sulfoxide (DMSO), followed by washing in water, but decreased again after subsequent drying and rewetting. Such reversible changes were not observed in unheated and dry-heated specimens. This suggested a hydrophobic structure formed during drying or plastic expansion of cell lumen due to steaming and soaking in DMSO. Although heat treatments reduced the hygroscopicity of the wood, steamed wood showed more swelling, i.e., lower dimensional stability than unheated and dry-heated wood. This is probably because steaming caused serious degradation of cell wall components, therefore loosening its fiber-reinforced structure restricting the swelling of the cell wall. When wood is exposed to alternate wetting and drying, steaming is not advisable because it may reduce the dimensional stability of the wood.
\end{abstract}

\section{Keywords:}

Steaming, dry-heating, dimensional stability, wet-dry cycle. 


\section{Introduction}

Heat treatment, which more or less reduces the hygroscopicity of wood, is an effective method for improving wood's dimensional stability and therefore its ability to withstand changes in humidity; this feature of heat-treated wood has been reported in studies since the 1950s (Seborg et al. 1953). The reduced hygroscopicity has been explained as resulting from irreversible chemical changes such as depolymerization and loss of hygroscopic hemicelluloses (Burmester 1975) and crosslinking reactions in lignins (Tjeerdsma et al. 1998, Tjeerdsma and Militz 2005).

Chemical changes observed in wood polymers include a reduction in the number of active $\mathrm{OH}$ groups, which has previously been considered a major contributing factor in reduced hygroscopicity of heat-treated wood. However, recent studies have suggested that the moisture sorption characteristics of wood are not simply determined by the number of active $\mathrm{OH}$ groups. Boonstra and Tjeerdsma (2006) observed no reduction in free $\mathrm{OH}$ groups after heat treatment, despite reduced hygroscopicity. Rautkari et al. (2013) observed a poor correlation between the equilibrium moisture content $(E M C)$ of heat-treated wood and the number of accessible $\mathrm{OH}$ groups; reduced hygroscopicity and restricted swelling of the heat-treated wood were explained instead by enhanced stiffness of the matrix polymers. This mechanism provides a reasonable explanation of the different effects of dry heating (heating in the absence of moisture) and steaming (heating in saturated water vapor) on the moisture sorption characteristics of wood (Obataya et al. 2002), as well as the effects of initial moisture content on the dimensional stability of steamed wood (Rautkari and Hill 2014). Altgen et al. (2016) discuss the different effects of dry heating and steaming in more detail.

On the other hand, it remains debatable whether the effects of heat treatment are irreversible or not. According to Borrega and Kärenlampi (2010), the largest EMC reduction is achieved by heating at intermediate humidities because of hornification, i.e., the formation of irreversible hydrogen bonds during water movement within the pore system of cell walls. Endo et al. (2016) also report similar effects of heating at intermediate humidities, but in this case, the reduced $E M C$ was largely recovered by moistening the wood in saturated water vapor at $25^{\circ} \mathrm{C}$. This temporary reduction in hygroscopicity is explained by the annealing-like physical aging of 
amorphous wood polymers, and is probably responsible for the unstable moisture sorption characteristics of dry-heated wood under cyclic changes in humidity (Majka et al. 2016).

It is important to understand the potential instability of heat-treated wood, in particular the effects of alternate wetting and drying, because it is sometimes used in exterior applications. According to Čermák et al. $(2015,2016)$, swelling of heat-treated wood increased and its antiswelling efficiency (ASE) decreased after six cycles of alternate wetting and drying. This phenomenon was attributed to a loss of decomposition residues bulking the wood cell wall. If true, such instability must depend on the heating method, i.e., dry heating or steaming, because the amount of water-leachable decomposition residues strongly depends on moisture conditions during heat treatment (Obataya et al. 2002, Altgen et al. 2016). However, little information is available on the effects of different heating methods on the dimensional instability of heat-treated wood under cyclic wetting and drying.

This paper describes dimensional changes in dry-heated and steamed spruce wood during alternate wetting and drying. We focused on changes in the dry and wet volume of the heat-treated wood, rather than on swelling and ASE values, which do not directly reflect structural changes in the wood cell wall. We also used an aprotic organic solvent as a swelling agent, in order to clarify the reversible formation and dissipation of hydrophobic structures during wet-dry cycles.

\section{Materials and methods}

\subsection{Heat treatment of wood samples}

Sitka spruce wood (Picea sitchensis) was cut into blocks with dimensions of 5 (longitudinal, L) $\times$ 25 (tangential, $\mathrm{T}) \times 25$ (radial, $\mathrm{R}) \mathrm{mm}$. The density of the specimens in absolutely dry conditions ranged from 298 to $321 \mathrm{~kg} / \mathrm{m}^{3}$. The specimens were heat-treated in the following manner.

Dry heating: specimens were completely dried on $\mathrm{P}_{2} \mathrm{O}_{5}$ at around $20^{\circ} \mathrm{C}$ under reduced pressure, and then heated in an oven at $120^{\circ} \mathrm{C}, 140^{\circ} \mathrm{C}, 160^{\circ} \mathrm{C}$, and $180^{\circ} \mathrm{C}$ under atmospheric pressure for 1,8 , and $24 \mathrm{~h}$. The treated specimens were cooled on dry $\mathrm{SiO}_{2}$ so that their mass and dimensions could be measured in absolutely dry conditions.

Steaming: specimens, which had been previously moistened at around $20^{\circ} \mathrm{C}$ and $100 \%$ 
relative humidity $(\mathrm{RH})$, were steamed at $120^{\circ} \mathrm{C}(199 \mathrm{kPa}), 140^{\circ} \mathrm{C}(361 \mathrm{kPa}), 160^{\circ} \mathrm{C}(618 \mathrm{kPa})$, and $180^{\circ} \mathrm{C}(1.00 \mathrm{MPa})$ for 10,30 , and 60 min using a specially designed autoclave (Dwianto et al. 1998). The temperature inside the autoclave reached the set temperatures within $10 \mathrm{~s}$ by the injection of pre-heated steam. The first $90 \mathrm{~s}$ of steaming were excluded from the treatment duration because of the delayed increase in the temperature of wood specimens. The steamed specimens were then cooled to room temperature, air-dried, and absolutely dried on $\mathrm{P}_{2} \mathrm{O}_{5}$ at room temperature under reduced pressure, so that their mass and dimensions could be measured.

A micrometer with a precision of $0.001 \mathrm{~mm}$ was used to measure wood dimensions. Eight specimens were used for each treatment condition, and the following discussion refers to the average values.

\subsection{Wet-dry cycling}

Figure 1 shows the experimental flow of alternate wetting and drying. After measuring the mass and dimensions of heat-treated specimens in dry conditions (Dry 1), specimens were soaked in water at room temperature, under reduced pressure, and then boiled gently at $95^{\circ} \mathrm{C}$ for $10 \mathrm{~min}$. The boiled specimens were leached in running water at room temperature for $1 \mathrm{wk}$, and their dimensions were measured (Wet 1). This process is referred to as "wetting" in this paper. Next, the wood specimens were air-dried for at least 3 days and then vacuum-dried on $\mathrm{P}_{2} \mathrm{O}_{5}$ at around $20^{\circ} \mathrm{C}$ to determine their mass and dimensions in absolutely dry conditions (Dry 2). Hereafter, this process is called "drying." This wetting and drying cycle was repeated four times (Wet $1 \sim$ Dry 4). The dry specimens were then soaked in dimethyl sulfoxide (DMSO) at around $20^{\circ} \mathrm{C}$ under reduced pressure for $1 \mathrm{wk}$, and their dimensions were measured (Wet $5^{*}$ ). The wood specimens were then soaked in methanol, which was replenished every day for $2 \mathrm{wk}$, in order to replace the DMSO in the specimens. The methanol was then in turn replaced by water, so that the wood dimensions were measured in water-swollen conditions (Wet 5). Finally, the wood specimens were dried (Dry 5) and then rewetted (Wet 6) in the manner described above. 


\section{Results and discussion}

\subsection{Mass loss due to heat treatments}

Mass loss (ML) from absolutely dry wood following heat treatment indicates thermal degradation of the wood constituents. In fact, most mechanical properties, including hygroscopicity, of heattreated wood depend strongly on ML (Millet and Gerhards 1972, Obataya et al. 2002, 2006, Borrega and Kärenlampi 2008, Altgen et al. 2016). Figure 2 shows ML due to heat treatment plotted against heating duration. Heating for longer periods of time at higher temperatures resulted in higher ML. In addition, ML was significantly higher after steaming and lower when subject to dry heating for the same duration, mainly because of the accelerated hydrolysis of polysaccharides in the presence of moisture.

\subsection{Changes in dry volume due to heat treatments and subsequent wet-dry cycling}

In this study, the volume of heat-treated wood is expressed as relative volume $\left(V / V_{\mathrm{D} 0}\right)$, which is the volume of treated wood $(V)$ divided by its dry volume in an unmodified state $\left(V_{\mathrm{D} 0}\right)$. Figure 3 shows the ML and $V / V_{\mathrm{D} 0}$ of heat-treated wood during wet-dry cycling. Dry heating $\left(180^{\circ} \mathrm{C}\right.$ for 24 h) and steaming $\left(180^{\circ} \mathrm{C}\right.$ for $\left.30 \mathrm{~min}\right)$ caused almost the same level of $\mathrm{ML}$ (ca. $5 \%$ ). However, steamed wood showed additional ML after the first wetting process, because of the loss of large amounts of water-soluble decomposition residues. ML remained almost unchanged during subsequent wet-dry cycles, and slightly increased after soaking in DMSO. Similar to ML, $V / V_{\mathrm{u} 0}$ decreased after heat treatments and wet-dry cycles. Figure 4 shows $V / V_{\mathrm{u} 0}$ values of all tested specimens in dry conditions (Dry 1 and Dry 5) plotted against ML. $V / V_{\mathrm{u} 0}$ decreased almost linearly with increasing ML, suggesting that wood shrinks as a result of loss of cell wall constituents caused by heat treatments and wet-dry cycles.

When we assume that the volume of cell lumen remains unchanged through the heat treatments and wet-dry cycles, the relative volume in dry conditions can be expressed by the following equation,

$$
V / V_{\mathrm{D} 0}=1-\frac{\mathrm{ML}}{100} \frac{\rho}{\rho_{s}}
$$


where $\rho$ is the density of wood in a dry condition, and $\rho_{\mathrm{s}}$ is that of the wood cell wall. Dashed lines in Figure 4 indicate $V / V_{\mathrm{D} 0}$ values calculated from eq. (1), assuming the possible range of $\rho_{\mathrm{s}}$ values to be $1300-1500 \mathrm{~kg} / \mathrm{m}^{3}$. The experimental values, especially for steamed wood, were always lower than the values calculated at the same ML. This suggests that heat treatment involves significant shrinkage of the cell lumen, in contrast with normal shrinkage due to dehydration, whereby the volume of cell lumen remains almost unchanged.

\subsection{Changes in wet volume due to heat treatments and subsequent wet-dry cycling}

Figure 5 shows the changes in wet volume of unheated and heat-treated specimens during wet-dry cycles. The wet volume of unheated wood remained unchanged, except for increased swelling when soaked in DMSO. Although some cell wall constituents were lost through repeated wetting, the wet volume of unheated wood was reasonably stable. That is, no hornification, i.e., irreversible reduction in wet volume, was observed in the present case.

In Figure 6, the wet volume of heat-treated wood is plotted against ML, and is shown to have overall decreased with increasing ML. Irrespective of ML, the wet volume of steamed wood (Wet 1) significantly decreased after the first drying and rewetting (Wet 2), and then remained unchanged (Wet 2 4). After a significant swelling when soaked in DMSO (Wet $5 *$ ), the wet volume reverted to its initial level (Wet $5 \approx$ Wet 1 ), but decreased again after subsequent drying and rewetting (Wet 6).

Here, we discuss the marked "reversible" changes in the wet volume of steamed wood. According to Čermák et al. $(2015,2016)$, swelling in heat-treated wood is influenced by the loss of decomposition residues during wet-dry cycling. Since the first wetting resulted in significant ML from steamed wood, the marked decrease in wet volume seems to be due to a loss of water-soluble decomposition residues. However, the wet volume of steamed wood remained unchanged during subsequent wet-dry cycling, despite additional ML, and recovered almost completely after soaking in DMSO. Therefore, changes in wet volume of the steamed wood cannot be explained by loss of any wood constituents. The term "hornification" is sometimes used to explain a reduction in wet volume due to alternate wetting and drying. However, strictly speaking, hornification is defined as 
an irreversible reduction in the accessibility and flexibility of cellulosic materials due to wet-dry cycles (Kato and Cameron 1999). In the case of our study, changes in the wet volume of steamed wood were reversible, and so hornification did not occur.

On the basis of the above considerations, we have speculated that a hydrophobic structure was formed in the steamed wood. Amorphous polysaccharides, particularly hemicelluloses, are rapidly hydrolyzed by steaming into low molecular weight sugars. At the same time, the framework polymers become hydrophobic, showing a reduction in active adsorption sites, such as $\mathrm{OH}$ groups. Immediately after steaming, large quantities of decomposition residues remaining in the cell wall (Dry 1) are responsible for maintaining intermolecular spacing, thus enabling the wood to achieve maximum wet volume during the first wetting (Wet 1). However, these "spacer" residues are removed by the first wetting, and a hydrophobic structure is then formed during drying (Dry 2). Since this hydrophobic structure is inaccessible to water, wood swelling is restricted during subsequent wet-dry cycles (Wet 2 4). On the other hand, as the hydrophobic structure is accessible to aprotic organic solvents, the wet volume is recovered by soaking in DMSO (Wet 5*) and a subsequent solvent exchange with water (Wet 5). By the following drying, the hydrophobic structure has reformed, and the wet volume is again reduced (Wet 6).

Another interpretation for the "reversible" changes in the wet volume is plastic expansion and shrinkage of cell lumen. In general, the volume of cell lumen remains almost unchanged during drying and wetting. However, the cell lumen may be anomalously expanded by steaming accompanied by the loosening of fiber-matrix structure (Wet 1). The expanded cell lumen turns to shrink when the water soluble decomposition residues are lost (Wet 2), but it is expanded again in DMSO involving remarkable swelling of the cell wall (Wet 5). This interpretation sounds reasonable when we consider the abnormal shrinkage due to steaming exhibited in Fig.3.

To date, the dimensional stability of heat-treated wood has been explained by irreversible chemical changes and loss of wood constituents. However, the results of the present study suggest that dimensional changes are partly recoverable by using aprotic organic solvents. Such reversibility should be taken into consideration when discussing the mechanisms of dimensional stabilization due to heat treatments. 


\subsection{Dimensional stability of heat-treated wood}

The wet volume of dry-heated wood was always lower than that of steamed wood, for the same ML. This agrees with the results of earlier investigations into the hygroscopicity and dimensional stability of heat-treated wood (Obataya et al. 2002, Rautkari and Hill 2014, Altgen et al. 2016). Figure 7 shows the relative volumetric swelling of heat-treated wood in the fourth dry-wet cycle as a function of ML. The dimensional stability of wood was improved by dry heating, due to a greater reduction in the wet compared to dry volume. In contrast, steamed wood showed greater swelling than untreated wood, because the reduction in dry volume was greater than for wet volume.

The degraded dimensional stability of steamed wood seems to contradict the general assumption that wood hygroscopicity is reduced by heat treatments. However, this finding can be explained by the different effects of steaming and dry heating on the moisture sorption characteristics of wood (Obataya et al. 2002): the EMC value of wood is reduced by both dry heating and steaming, but that of steamed wood increases steeply when RH increased above $60 \%$, whereas that of dry-heated wood monotonically decreases with increasing $\mathrm{RH}$. With regard to moisture sorption characteristics, the effects of dry heating are qualitatively similar to those of a formaldehyde treatment involving cross-linking between amorphous wood polymers (Yasuda et al. 1995). In dry heating, the cross-linking reaction occurs under dry conditions where intermolecular spacing is minimized, and effectively restricts wood swelling in water. In contrast, no such structure is formed in steamed wood because the wood is modified in fully swollen conditions. In addition, the hydrolysis of wood polymers, such as hemicelluloses, may loosen the fiber-reinforced structure of the wood cell wall and weaken matrix stiffness (Altgen et al. 2016). This may result in greater shrinkage when in a dry condition (Fig. 4), as well as greater swelling of the wood cell wall, involving expansion of the cell lumen.

When wood is used under dry, ambient air conditions, its dimensional stability is improved by heat treatment because its $E M C$ is more or less reduced, irrespective of the heating method. However, if the wood is exposed to alternate wetting and drying, such as when used in exterior applications, heat treatment by steaming is not advisable because it may degrade the 
dimensional stability of the wood under such severe service conditions.

\section{Conclusions}

Spruce wood specimens were steamed and dry-heated at $120-180^{\circ} \mathrm{C}$, and their volumes were measured during repeated wet-dry cycles. The irregular changes observed in the wet volume of steamed wood suggested that a hydrophobic structure was formed in the wood cell wall, otherwise the cell lumen was plastically expanded by steaming or soaking in DMSO. Such a change was not observed in unheated and dry-heated wood specimens. This greater swelling of steamed wood suggested a degraded dimensional stability, in comparison with the improved dimensional stability of wood subjected to dry heating. The dimensional instability of steamed wood was attributed to a lack of tight cross-linking, as well as the loosening of the cell wall structure.

\section{References}

Altgen M, Hofmann T, Militz H (2016) Wood moisture content during the thermal modification process affects the improvement in hygroscopicity of Scots pine sapwood. Wood Sci Technol 50(6):1181-1195

Boonstra MJ, Tjeerdsma B (2006) Chemical analysis of heat treated softwoods. Holz Roh Werkst 64(3):204-211

Borrega M, Kärenlampi PP (2008) Mechanical behavior of heat-treated spruce (Picea abies) wood at constant moisture content and ambient humidity. Holz Roh Werkst 66(1):63-69

Borrega M, Kärenlampi PP (2010) Hygroscopicity of heat-treated Norway spruce (Picea abies) wood. Eur J Wood Prod 68(2):233-235

Burmester A (1975) Zur Dimensionsstabilisierung von Holz. Holz Roh Werkst 33:333-335

Čermák P, Rautkari L, Horáček P, Saake B, Rademacher P, Sablik P (2015) Analysis of dimensional stability of thermally modified wood affected by re-wetting cycles. Biores 10(2):3242-3253

Čermák P, Vahtikari K, Rautkari L, Laine K, Horáček P, Baar J (2016) The effect of wetting cycles on moisture behaviour of thermally modified Scots pine (Pinus sylvestris L.) wood. J 
Materials Sci 51(3):1504-1511

Dwianto W, Morooka T, Norimoto M (1998) A method of measuring viscoelastic properties of wood under high-temperature and high-pressure steam conditions (in Japanese). Mokuzai Gakkaishi 44(2):77-81

Endo K, Obataya E, Zeniya N, Matsuo M (2016) Effects of heating humidity on the physical properties of hydrothermally treated spruce wood. Wood Sci Technol 50(6):1161-1179

Kato KL, Cameron RE (1999) Structure-property relationships in thermally aged cellulose fibers and paper. J Appl Polym Sci 74(6):1465-1477

Majka J, Czajkowski Ł, Olek W (2016) Effects of cyclic changes in relative humidity on the sorption hysteresis of thermally modified spruce wood. Biores 11(2):5265-5275

Millet MA, Gerhards CC (1972) Accelerated aging: residual weight and flexural properties of wood heated in air at $115^{\circ} \mathrm{C}$ to $175^{\circ} \mathrm{C}$. Wood Sci 4(4):193-201

Obataya E, Higashihara T, Tomita B (2002) Hygroscopicity of heat-treated wood III. Effect of steaming on the hygroscopicity of wood (in Japanese). Mokuzai Gakkaishi 48(5):348-355

Obataya E, Shibutani S, Hanata K, Doi S (2006) Effects of high temperature kiln drying on the practical performances of Japanese cedar wood (Cryptomeria japonica) I: changes in hygroscopicity due to heating. J Wood Sci 52(1):33-38

Rautkari L, Hill CAS, Curling S, Jalaudin Z, Ormondroyd G (2013) What is the role of the accessibility of wood hydroxyl groups in controlling moisture content? J Mater Sci 48(18): 63526356

Rautkari L, Hill CAS (2014) Effect of initial moisture content on the anti-swelling efficiency of thermally modified Scots pine sapwood treated in a high-pressure reactor under saturated steam. Holzforschung 68(3):323-326

Seborg RM, Tarkow H, Stamm AJ (1953) Effect of heat upon the dimensional stabilization of wood. J For Prod Res Soc 3(9):59-67

Tjeerdsma BF, Boonstra M, Pizzi A, Tekely P, Militz H (1998) Characterization of thermally modified wood: molecular reasons for wood performance improvement. Holz Roh Werkst 56:149153 
Tjeerdsma BF, Militz H (2005) Chemical changes in hydrothermal treated wood: FTIR analysis of combined hydrothermal and dry heat-treated wood. Holz Roh Werkst 63(2):102-111

Yasuda R, Minato K, Norimoto M (1995) Moisture adsorption thermodynamics of chemically modified wood. Holzforschung 49(6):548-554 


\section{Figure legends}

Fig. 1 Experimental flow

Fig. 2 Mass loss (ML) due to heat treatments plotted against heating duration

Circles, heated at $120^{\circ} \mathrm{C}$; triangles, heated at $140^{\circ} \mathrm{C}$; squares, heated at $160^{\circ} \mathrm{C}$; diamonds, heated at $180^{\circ} \mathrm{C}$; open symbols, heated dry; filled symbols, steamed.

Fig. 3 Effects of alternate wetting and drying on mass loss (ML) and relative volume $\left(V / V_{\mathrm{D} 0}\right)$ of unheated and heat-treated wood in dry conditions

Crosses, unheated; open circles, heated dry at $180^{\circ} \mathrm{C}$ for $24 \mathrm{~h}$; filled circles, steamed at $180^{\circ} \mathrm{C}$ for $30 \mathrm{~min}$.

Fig. 4 Plots of relative volume $\left(V / V_{\mathrm{D} 0}\right) v s$. mass loss (ML) in dry conditions

Circles, Dry 1; squares, Dry 5; open symbols, heated dry; filled symbols, steamed; Dashed lines, calculated values based on the assumption that the volume of cell lumen remains unchanged; a, $\rho_{\mathrm{s}}=1300 \mathrm{~kg} / \mathrm{m}^{3}, \mathrm{~b}, \rho_{\mathrm{s}}=1500 \mathrm{~kg} / \mathrm{m}^{3}$

Fig. 5 Effects of alternate wetting and drying on the relative volume $\left(V / V_{\mathrm{D} 0}\right)$ of unheated and heat-treated wood in wet conditions

Crosses, unheated; open circles, heated dry at $180^{\circ} \mathrm{C}$ for $24 \mathrm{~h}$; filled circles, steamed at $180^{\circ} \mathrm{C}$ for $30 \mathrm{~min}$. The asterisk indicates the swelling when soaked in DMSO (Wet $5^{*}$ ), which is distinguished from soaking in water (Wet 5).

Fig. 6 Relative volume $\left(V / V_{\mathrm{D} 0}\right)$ values in wet conditions plotted against mass loss (ML)

Open circles, Wet 1; filled circles, Wet 2; filled squares, Wet 4; crosses, Wet 5*; open squares, Wet 5; filled diamonds, Wet 6. The ML value for each condition was defined as that determined in the subsequent dry condition. 
Fig. 7 Relative swelling of heat-treated wood in the $4^{\text {th }}$ dry-wet cycle, plotted against mass loss (ML)

Open circles, heated dry; filled circles, steamed. The relative swelling is defined as $V / V_{\mathrm{D} 0}($ Wet 4$)-V / V_{\mathrm{D} 0}($ Dry 4$)$. 
Fig. 1.

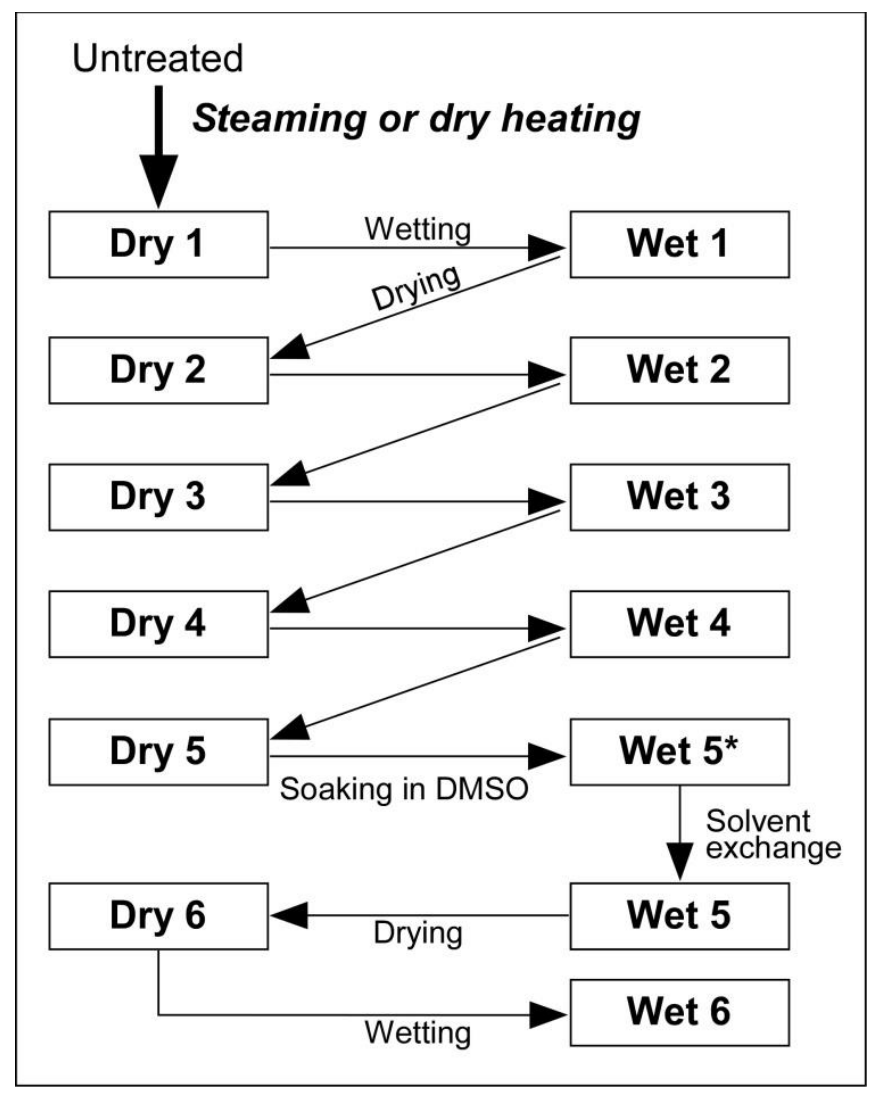


Fig. 2 .

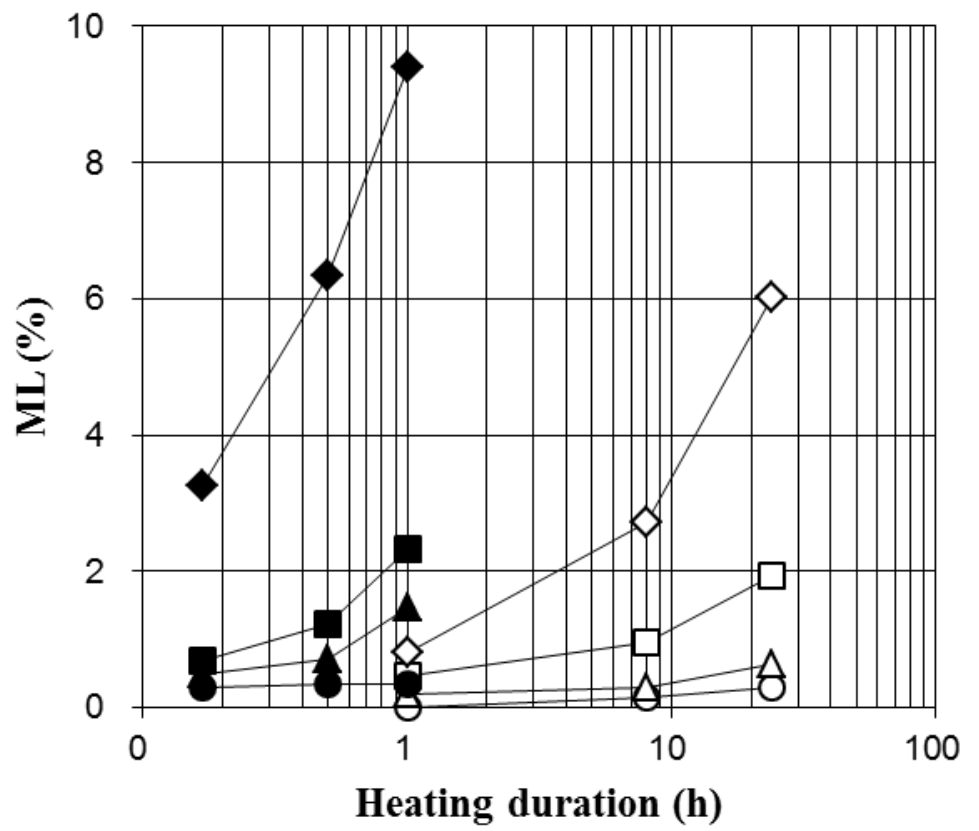


Fig. 3.
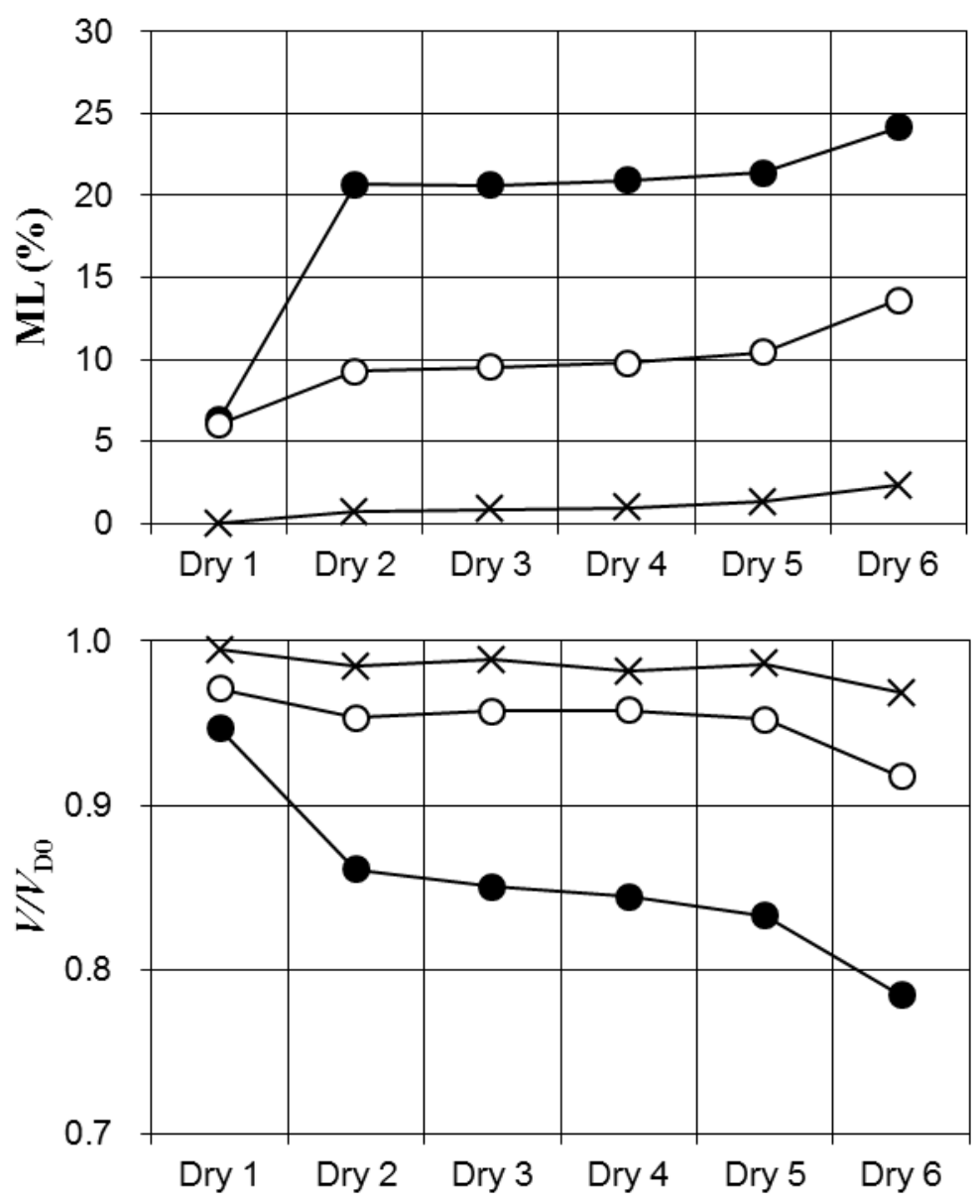
Fig. 4.

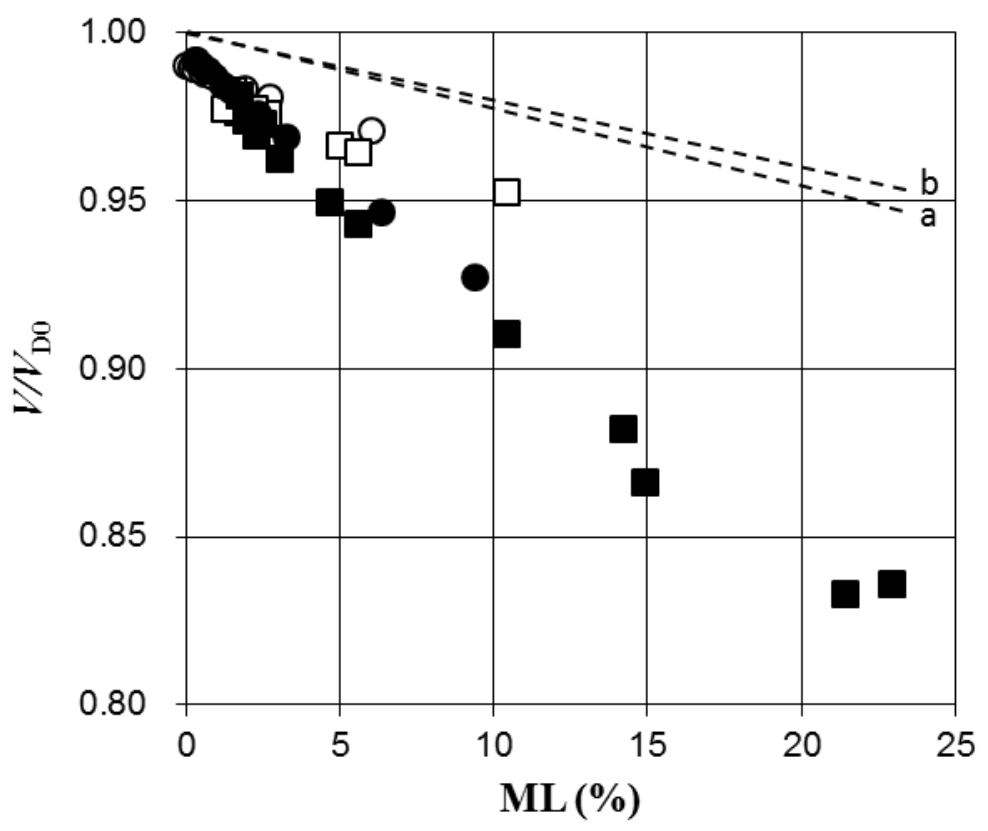


Fig. 5.

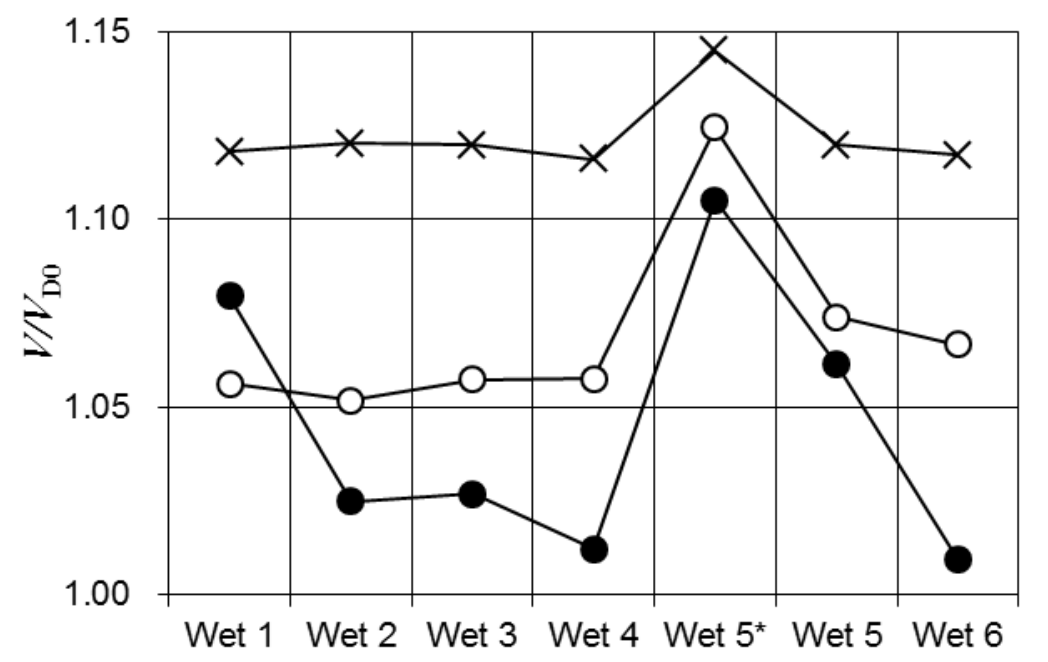


Fig. 6.
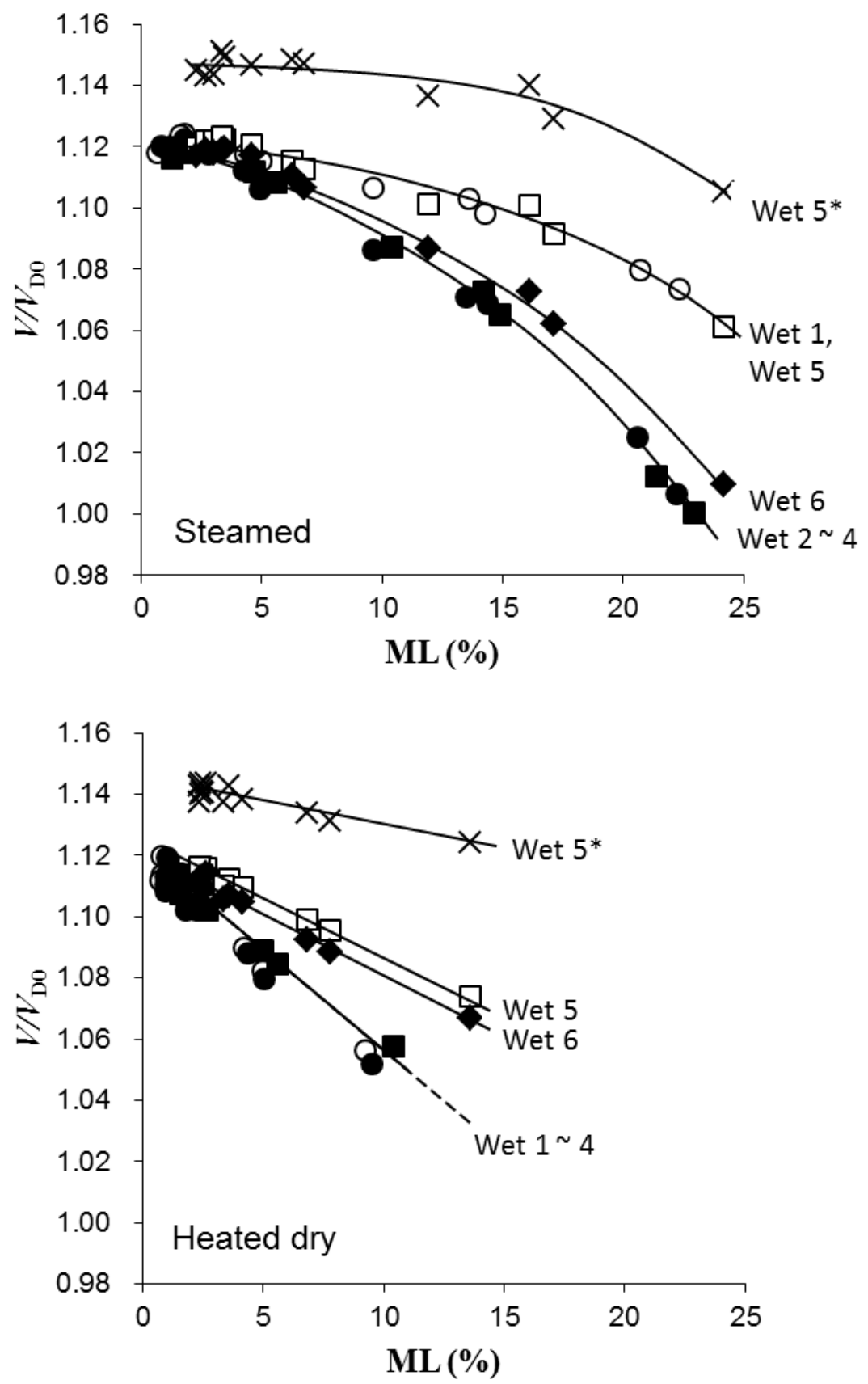
Fig. 7.

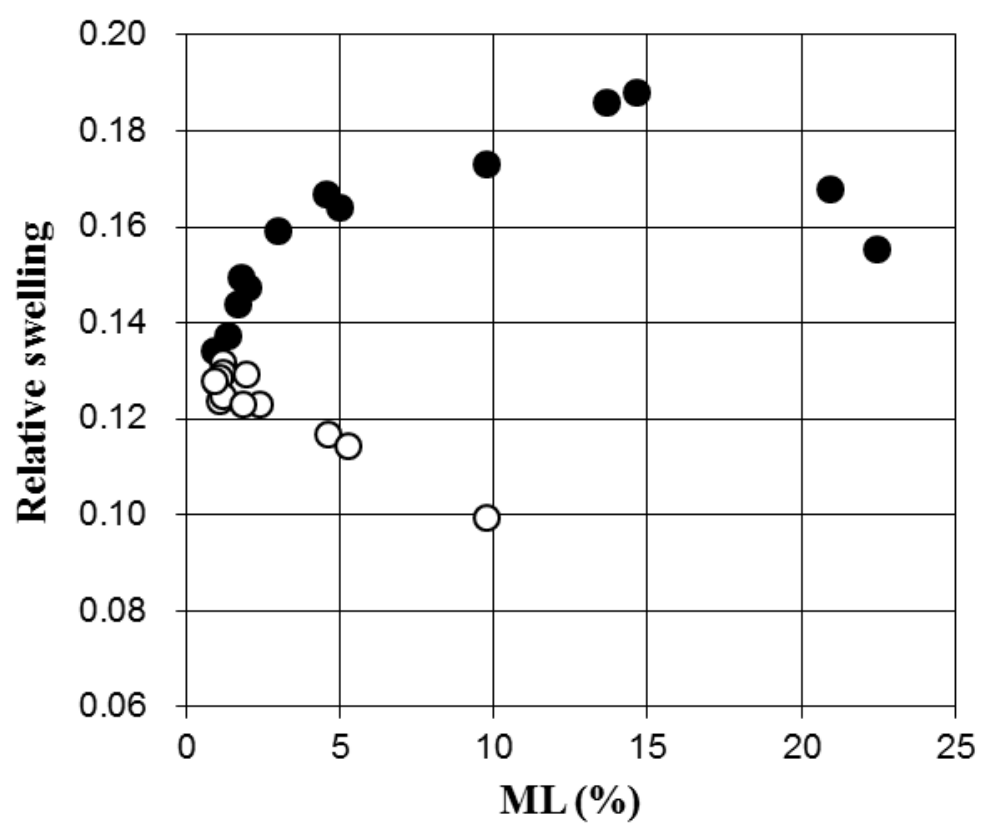

